\title{
Thrombomodulin: A New Marker for Placental Abruption
}

\author{
Urania Magniples, Daniel W. Chan, Debra Bruzek, J oshua A. Copel, Chaur-Dong Hsu
}

From the Departments of Obstetric s and Gynecology, Yale University, New Haven, CT, and J ohns Hopkins University Sc hool of Medic ine, Ba Itimore, MD, USA

\section{Summary}

Thrombomodulin (TM), a marker of endothelial cell damage, has been localized to the placental syncytiotrophoblast. A prospective cohort study of twenty-five pregnant women who were admitted with a clinical diagnosis of placental abruption was undertaken. Abruption was confirmed after delivery in eight cases (Group 1). Group 2 consisted of seventeen patients with no clinical or pathologic evidence of placental abruption after delivery. TM was significantly elevated in Group $1(71.59 \pm 5.35$ vs. $48.29 \pm 3.53 \mathrm{ng} / \mathrm{ml}, \mathrm{p}=0.001)$. The sensitivity and specificity of TM $\geq 60 \mathrm{ng} / \mathrm{ml}$ as a marker for abruption was 87.5 and $76.5 \%$, respectively. In comparison, the sensitivity of an abnormal coagulation profile, maternal Kleihauer-Betke and ultrasound in patients with abruption was $0,16.7$ and $28.6 \%$, respectively. TM is a highly sensitive and specific marker for acute placental abruption.

\section{Introduction}

Placental abruption complicates approximately $1 \%$ of pregnancies and is a major contributor to perinatal and maternal morbidity and mortality. Risk factors for abruption include advanced maternal age, smoking, hypertension, trauma, cocaine, the presence of an anomalous fetus, sudden uterine decompression and previous history of abruption $(1,2,3)$. Diagnostic difficulties remain and clinical symptomatology, such as unexplained back or abdominal pain and vaginal bleeding, is still the mainstay of diagnosis. However, antepartum vaginal bleeding is absent in $20-35 \%$ of cases. The diagnosis is not made until after delivery in 38\% of cases (4). Diagnostic tests such as the Kleihauer-Betke fetal red cell screen lack sensitivity and specificity (5). Coagulopathy is rarely detected with a live fetus but may be present in $35-38 \%$ of cases with a dead fetus $(1,6)$. The Ddimer latex agglutination slide test has been shown in one study to be a more sensitive marker than other laboratory measures of coagulation (sensitivity of $67 \%$ compared to less than $20 \%$ for thrombocytopenia, prolonged prothrombin time or hypofibrinogenemia) (7). Elevated maternal serum alpha-fetoprotein, which in the second trimester has been associated with a ten-fold risk of placental abruption, has wide fluctuations in the third trimester and is therefore not clinically useful (8). Serum CA 125, which is released by the decidua, is also elevated in some cases of placental abruption but does not appear to be a sensitive marker (9). Ultrasound can be used to diagnose large hematomas and those that have already calcified but is not useful in detecting acute bleeding. In the setting of blunt trauma, ultrasound and the

Correspondence to: Dr. Urania Magriples, Department of Obstetrics,Yale University School of Medicine, 333 Cedar Street, PO Box 3333, New Haven, CT 06510, USA - Tel.. + 1 203-785-3091; FAX Number: +1 203-785-6885 presence of fetal distress are of more utility than coagulation profiles or Kleihauer-Betke screens, and when positive usually heralds a catastrophic outcome $(10,11)$.

Placental abruption causes activation of the clotting cascade and endothelial damage which trigger mediator release. One mediator, thrombomodulin (TM), is a vascular endothelial cell receptor for thrombin. In addition to endothelial cells, syncytiotrophoblast also bears TM on its membranes (12). TM is the receptor for the activation of protein $\mathrm{C}$ by thrombin and neutralizes thrombin clotting activity. It can be detected in the circulation after damage of the endothelial cell and syncytiotrophoblast. This study was performed to determine whether TM would be a clinically useful marker for placental abruption.

\section{Materials and Methods}

We performed a prospective cohort study of twenty-five patients admitted with suspected placental abruption. The study was approved by the Yale University Human Investigations Committee and verbal consent was obtained from each of the patients at the time of recruitment. Criteria for inclusion were vaginal bleeding in the absence of placenta previa, a hyperstimulated contraction pattern or suspected abdominal trauma from a motor vehicle accident, fall or assault. Women with preeclampsia were excluded as TM levels have been shown to be elevated in these patients (13). Routine laboratory work included hematocrit, platelet count, prothrombin time, partial thromboplastin time, fibrinogen, Kleihauer-Betke (acid elution test for fetal red cells) and urine toxicology for cocaine. Fetal ultrasound was performed on all stable patients to determine the presence of a retroplacental clot or placental inhomogeneity.

Maternal venous blood samples were obtained on admission of subjects to the labor floor. The samples were centrifuged at $2000 \mathrm{~g}$ for $15 \mathrm{~min}$ at $4^{\circ} \mathrm{C}$ and the supernatants were stored in polypropylene tubes at $-70^{\circ} \mathrm{C}$ and assayed at a later date. Samples were not subjected to freeze-thaw cycles before analysis. Plasma TM was determined using a two-site ELISA (Asserachrom Thrombomodulin, Diagnostica Stago, Asnieres, France), prepared with two monoclonal antihuman TM antibodies. Inter-assay and intra-assay coefficients of variance of TM averaged 8 and $7 \%$, respectively.

After delivery, placental histopathology and delivery notes were reviewed. A true positive was defined as the clinical diagnosis of placental abruption by the attending physician at the time of delivery and/or histological confirmation. The attending physician was unaware of the TM level at the time of delivery. Differences between groups were determined by Student's t-tests. A Receiver Operator Characteristic (ROC) curve was constructed as a graphic representation of the relation between sensitivity and specificity with varying TM values and the presence of abruption. A p value less than 0.05 was considered significant. The data are presented as mean $\pm \mathrm{SEM}$.

\section{Results}

Abruption was confirmed after delivery in eight cases (Group 1). Group 2 consisted of seventeen patients with no clinical or pathologic 
Table 1 Maternal characteristics

\begin{tabular}{lccc}
\hline & $\begin{array}{c}\text { Group 1 } \\
\text { (Abruption) }\end{array}$ & $\begin{array}{c}\text { Group 2 } \\
\text { (Non-Abruption) }\end{array}$ & p \\
\hline $\mathrm{N}$ & 8 & 17 & \\
Age (yr) & $26.6 \pm 2.2$ & $24.1 \pm 1.5$ & NS \\
Race White & $4(50 \%)$ & $6(35.3 \%)$ & NS \\
Black & $4(50 \%)$ & $10(58.8 \%)$ & \\
Hispanic & 0 & $1(5.9 \%)$ & NS \\
Gravidity & $3.0 \pm 0.7$ & $2.1 \pm 0.4$ & NS \\
Parity & $1.1 \pm 0.4$ & $0.9 \pm 0.4$ & NS \\
GA (wk) & $33.6 \pm 1.6$ & $31.9 \pm 1.4$ & 0.001 \\
\hline TM (ng/m1) & $71.59 \pm 5.35$ & $48.29 \pm 3.53$ &
\end{tabular}

Data are presented as mean \pm standard error

$\mathrm{GA}$ : gestational age

TM: thrombomodulin

NS: non-significant

Table 2 Laboratory values of patients with placental abruption

\begin{tabular}{|c|c|c|c|c|}
\hline $\mathrm{Pt}$ & $\begin{array}{c}\mathrm{TM} \\
(\mathrm{ng} / \mathrm{ml})^{*}\end{array}$ & US & $\begin{array}{c}\text { Kleihauer- } \\
\text { Betke }\end{array}$ & $\begin{array}{c}\text { Coagulation } \\
\text { profile }\end{array}$ \\
\hline 1 & 66.4 & neg & ND & $\mathrm{nl}$ \\
\hline 2 & 70.6 & neg & neg & $\mathrm{n} l$ \\
\hline 3 & 72.3 & neg & neg & $\mathrm{n} 1$ \\
\hline 4 & 74.0 & ND & ND & $\mathrm{nl}$ \\
\hline 5 & 80.1 & neg & neg & $\mathrm{n} 1$ \\
\hline 6 & 100.3 & neg & neg & $\mathrm{n} 1$ \\
\hline 7 & 47.8 & $\begin{array}{c}\text { pos } \\
\text { (placental clot) }\end{array}$ & neg & $\mathrm{nl}$ \\
\hline 8 & 61.3 & $\begin{array}{c}\text { pos } \\
\text { (placental clot) }\end{array}$ & $1.7 \%$ & $\mathrm{nl}$ \\
\hline
\end{tabular}

\footnotetext{
* Positive $\mathrm{TM} \geq 60 \mathrm{ng} / \mathrm{ml}$

TM: thrombomodulin

ND: not done

neg: negative

nl: normal

pos: positive

pt: patient

US: ultrasound
}

evidence of placental abruption after delivery. The clinical characteristics of the groups are presented in Table 1. None of the patients had clinical evidence of DIC before or after their delivery. There was no statistically significant difference in age, race, gravidity, parity or gestational age between the groups. No patients in Group 1 had urine toxicology positive for cocaine; there was one positive result in Group 2. TM was significantly greater in Group 1 ( $71.59 \pm 5.35$ vs. $48.29 \pm 3.53 \mathrm{ng} / \mathrm{ml}, \mathrm{p}=0.001)$. The test results of the patients with abruption are presented in Table 2 .

Six patients had acute abruption at delivery. Defining $\mathrm{TM} \geq 60 \mathrm{ng} / \mathrm{ml}$ as positive, (see Fig. 1), the sensitivity and specificity of TM as a marker for abruption were 87.5 and $76.5 \%$, respectively. All patients with acute abruption had plasma TM greater than $60 \mathrm{ng} / \mathrm{ml}$. The two

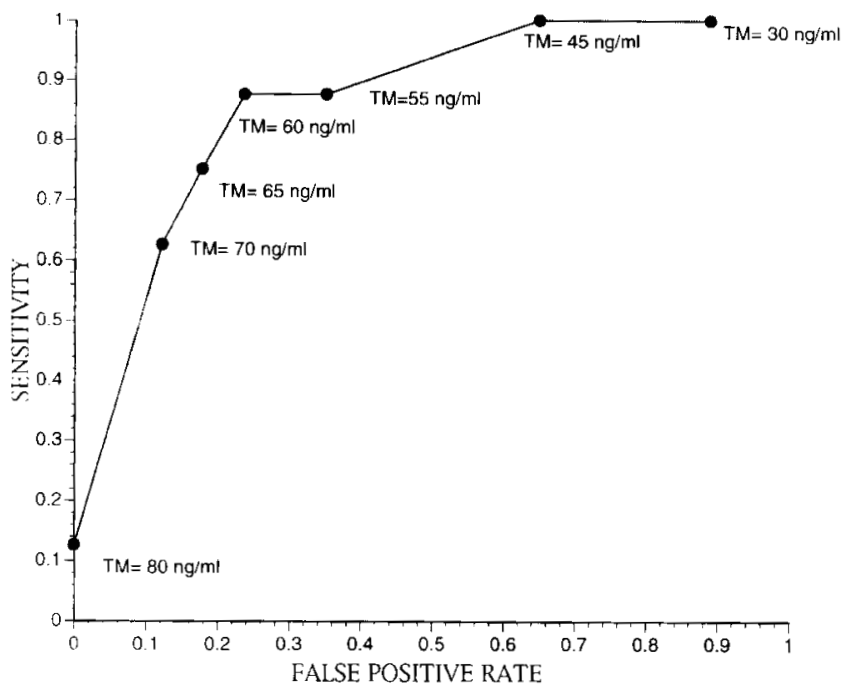

Fig. 1 Receiver operator characteristic curve comparing sensitivity and false-positive rate for detecting placental abruption at different TM values

Table 3 Comparison of sensitivity and specificity of tests

\begin{tabular}{llc}
\hline & Sensitivity & Specificity \\
\hline $\mathrm{TM} \geq 60 \mathrm{ng} / \mathrm{ml}$ & $7 / 8(87.5 \%)$ & $13 / 17 \quad(76.5 \%)$ \\
Ultrasound & $2 / 7(28.6 \%)$ & $16 / 16 \quad(100 \%)$ \\
$\mathrm{TM} \geq 60 \mathrm{ng} / \mathrm{ml}$ and & $8 / 8(100 \%)$ & $13 / 17 \quad(76.5 \%)$ \\
$\mathrm{Ultras}$ ound & $1 / 6(16.7 \%)$ & $12 / 12 \quad(100 \%)$ \\
Kleihauer-Betke & $0 / 8(0 \%)$ & $12 / 12 \quad(100 \%)$ \\
\hline
\end{tabular}

TM: thrombomodulin

patients with pathologically diagnosed chronic abruption were the only patients with ultrasonography showing retroplacental hematomas. One of these patients had a negative TM level of $47.8 \mathrm{ng} / \mathrm{ml}$ and the other a TM level of 61.3, a borderline value at the cut-off of the Receiver Operator Characteristic curve. In comparison, the sensitivity of an abnormal coagulation profile, maternal Kleihauer-Betke and ultrasound in Group 1 were $0,16.7$ and $28.6 \%$, respectively (Table 3 ). When the combination of TM and ultrasound was used, the sensitivity and specificity were 100 and $76.5 \%$, respectively.

\section{Disc ussion}

Our study shows that TM is a highly sensitive and specific marker for placental abruption and may have more clinical relevance than traditional markers such as coagulation profile, Kleihauer-Betke fetal red cell screen and ultrasound. TM is a cell surface glycoprotein released from damaged endothelial cells and trophoblast and acts as a cofactor for thrombin, which catalyzes the activation of protein $\mathrm{C}$. Elevated circulating levels of TM have been found in patients with endothelial disorders such as severe preeclampsia, disseminated 
intravascular coagulopathy, thrombotic thrombocytopenic purpura and systemic lupus erythematosus (13). Patients with preeclampsia were excluded from this study as this would be a confounding variable. None of the patients in the study had clinical evidence of DIC before or after their delivery.

The wide distribution of TM on vascular endothelium and in syncytiotrophoblast makes it an ideal marker for placental separation. TM is an acute marker with a relatively short half-life. If there is stabilization of the abruption and organization of the hematoma, TM may not be elevated. This physiology may explain the observation of TM elevation in acute but not in chronic placental abruption.

Microscopically, retroplacental hematomas consist of red cells and fibrin. The amount of fibrin increases as the lesion ages. As the syncytiotrophoblast, vascular endothelium and villous stroma undergo progressive necrosis this is seen histologically as an infarct overlying the hematoma (14). As the clot and infarct become organized and calcified, the abruption can be readily seen on ultrasound. This pattern was seen in the two subjects with chronic abruption. Patient 7 (see Table 2) presented with a 1 month history of vaginal bleeding, severe intrauterine growth retardation and was delivered secondary to fetal decelerations. The placenta revealed 50\% infarct with marked intervillous fibrin and clot. Patient 8 presented one month after a motor vehicle accident with fetal decelerations and vaginal bleeding. After delivery, placental histology revealed a $7 \times 6 \mathrm{~cm}$ placental infarct (10\% of its volume).

There were 4 cases of elevated TM who went on to have normal uncomplicated deliveries without evidence of abruption. The vaginal bleeding resolved and there was no clinical evidence of abruption at the time of delivery. They may represent disruptions of the syncytiotrophoblast, which were clinically and pathologically insignificant.

The combination of TM and ultrasound as a "double marker" for abruption detected all cases of abruption. TM may prove useful in the antenatal diagnosis of abruption in the setting of trauma or unexplained vaginal bleeding. The diagnosis of abruption may impact on the clinical monitoring of the fetus as well as on decision-making in the hospitalization and delivery plan. Further studies are ongoing to further elucidate the role of TM as a clinically useful marker in patients at risk for placental abruption.

\section{References}

1. Green-Thompson RW. Antepartum hemorrhage. Clin Obstet Gynecol 1982; 9: 479-515.

2. Eriksen G, Wohlert M, Ersbak V, Hvidman L, Hedegaard M, Skajaa K. Placental abruption. A case-control investigation. Br J Obstet Gynaecol 1991; 98: 448-52.

3. Raymond EG, Mills JL. Placental abruption: Maternal risk factors and associated fetal conditions. Acta Obstet Gynecol Scand 1993; 72: 633-9.

4. Hurd WH, Miodovnik M, Hertzberg V, Lavin JP. Selective management of abruptio placentae: a prospective study. Obstet Gynecol 1983; 61: 467-73.

5. Emery CL, Morway LF, Chung-Park M, Wyatt-Ashmead J, Sawady J, Beddow TD. The Kleihauer-Betke test. Clinical utility, indication and correlation in patients with placental abruption and cocaine use. Arch Pathol Lab Med 1995; 119: 1032-7.

6. Pritchard JA, Brekken AL. Clinical and laboratory studies on severe abruptio placentae. Am J Obstet Gynecol 1967; 97: 681-96.

7. Nolan TE, Smith RP, Devoe LD. A rapid test for abruptio placentae: Evaluation of a D-dimer latex agglutination slide test. Am J Obstet Gynecol 1993; 169: 265-9.

8. Katz VL, Chescheir NC, Cefalo RC. Unexplained elevations of maternal serum alpha-fetoprotein. Obstet Gynecol Surv 1990; 45: 719-26.

9. Williams MA, Hickok DE, Zinghelm RW, Zebelman AM. Maternal serum CA 125 levels in the diagnosis of abruptio placentae. Obstet Gynecol 1993; 82: 808-12.

10. Dahmus MA, Sibai BM. Blunt abdominal trauma: are there any predictive factors for abruptio placentae or maternal-fetal distress? Am J Obstet Gynecol 1993; 169: 1054-9.

11. Towery R, English TP, Wisner D. Evaluation of pregnant women after blunt injury. J Trauma 1993; 35: 731-5.

12. Maruyama I, Bell CE, Majerus PW. Thrombomodulin is found on endothelium of arteries, veins, capillaries and lymphatics, and on syncytiotrophoblast of human placenta. J Cell Biol 1985; 101: 363-71.

13. Hsu CD, Iriye B, Johnson TR, Witter FR, Hong SF, Chan DW. Elevated circulating thrombomodulin in severe preeclampsia. Am J Obstet Gynecol 1993; 169: 148-9 and Am J Obstet Gynecol 1994; 171: 1165.

14. Gershell DJ, Kraus FT, Riffle MB. Diseases of the placenta. In: Kurman RJ, ed. Blaustein's pathology of the female genital tract. 3rd ed. New York: Springer-Verlag, 1987: 769-834.

Received June 5, 1998 Accepted after resubmission September 18, 1998 